Florida International University

FIU Digital Commons

Electrical and Computer Engineering Faculty

Publications

4-2014

\title{
A Downsizing Strategy for Combinatorial PMSG Based Wind Turbine and Micro-SMES System Applied in Standalone DC Microgrid
}

Arif I. Sarwat

Amirhasan Moghadasiriseh

Follow this and additional works at: https://digitalcommons.fiu.edu/ece_fac

Part of the Electrical and Computer Engineering Commons

This work is brought to you for free and open access by the College of Engineering and Computing at FIU Digital Commons. It has been accepted for inclusion in Electrical and Computer Engineering Faculty Publications by an authorized administrator of FIU Digital Commons. For more information, please contact dcc@fiu.edu. 


\section{A Downsizing Strategy for Combinatorial PMSG Based Wind Turbine and Micro-SMES System Applied in Standalone DC Microgrid New Energy Economy}

Arif I. Sarwat ${ }^{* 1}$, A.H. Moghadasi ${ }^{* 2}$,

Electrical Engineering Department, Center of Energy, Power \& Sustainability (EPS), Florida International University (FIU), Miami 33174, USA

${ }^{* 1}$ asarwat@fiu.edu, 2amogh004@fiu.edu

\begin{abstract}
This paper presents a combinatorial standalone permanent magnet synchronous generator (PMSG) based variable speed wind turbine (VSWT) and small-size superconducting magnetic energy storage (SMES) system into the DC microgrid system. The principal purpose of SMES system is to preserve power balance by absorbing power during peak wind generation and to release it during low power generation. This work accomplished by describing the optimized design of the SMES solenoid coil, ensuring the desired energy storage capacity based on the simulated annealing (SA) algorithm. More importantly, the new control technique is developed for bi-directional DC-DC converter to level output power of the wind turbine depending on the demand thereby reducing the capacity of the DC-DC converter system. Detailed simulation studies implemented in PSCAD/EMTDC corroborate the superior robustness and balancing performance of the proposed micro-SMES controller with an optimal coil size under various situations including variable wind speed. This combination will result in "scaling-factors" knowledge through downsizing strategy which will lead to the most efficient system from cost cutting, energy savings, and downsizing viewpoints.
\end{abstract}

\section{Keywords}

DC Microgrid; Permanent Magnet Synchronous Generator (Pmsg); Superconducting Magnetic Energy Storage (Smes); Simulated Annealing (Sa); Wind Turbine Wind Turbine

\section{Introduction}

Recently while tracking several outages and power disturbances due to human error, poor maintenance and extreme weather events; , the concept of microgrids with Distributed Energy Resources (DER) and loads have been envisioned as the controversial issue for future electrical power system [1], [2]. In the context of microgrid, customers and DER units can be connected at the DC bus operating in intentional or non-intentional islanding modes which is formally called standalone DC microgrid [3], [4].

Moreover, wind turbines with standalone mode of operation are becoming more and more common which can have a critical role in sustainable energy development and implementation of a smart dc distribution system [5]. The consistency of the Variable Speed Wind Turbine (VSWT) can be enhanced via a Permanent Magnet Synchronous Generator (PMSG) where has received special attentions in a standalone mode owing to its simplicity, low maintenance requirements as well as high efficiency operation [6]. Due to intermittent nature of wind, the power generated (DC grid) cannot follow load demand effectively thus few additional energy storages are required to improve the power system stability [7].

The Superconducting Magnetic Energy Storage (SMES) system is a new technology that has been recognized as most reliable and effective option to regulate power fluctuations and maintain the stability of the voltage in power system [8]-[10]. SMES systems store energy in a magnetic field created by DC current flowing through a superconducting coil that has been cryogenically cooled. Last progresses in power electronics technology and the cryogenic systems have made the SMES system more outstanding to any other Energy Storage Systems (ESS). Generally speaking, the SMES system has a number of superior performances over the DC microgrid, such as high eficiency (up to 90\%), fast response capability and no deteriorations [11].

In recent year, several efforts have been documented on different operational modes and control strategies of VSWT-PMSG based DC microgrid along with energy storage system [12], [13]. 


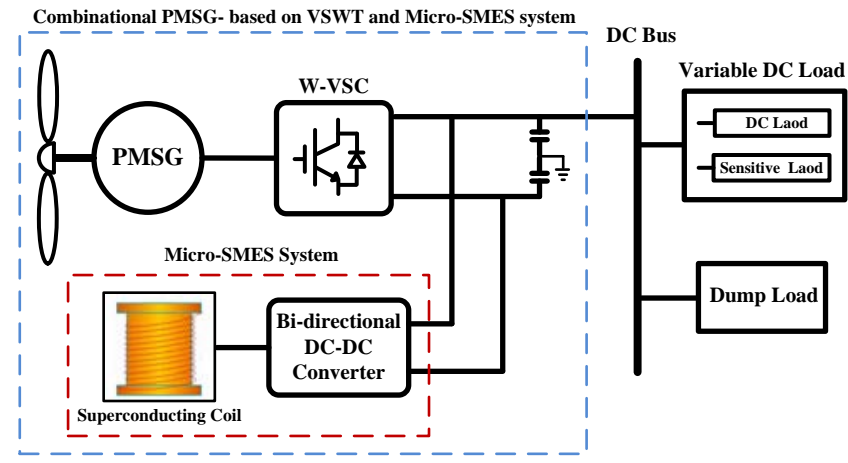

FIG. 1 PMSG-BASED STANDALONE VSWT WITH MICRO-SMES SYSTEM IN DC MICROGRID

However, these papers are mostly focused on AC grid connected system in which batteries and fuel cells are commonly utilized as energy storage device and no previous work has been reported on standalone dc microgrid along with SMES system.

This article attempts to fill this void by presenting a combinatory standalone VSWT-PMSG and microSMES system in order to stabilize the dc-link voltage, thereby smoothing the output power simultaneously. First, the desired energy storage capacity of the microSMES coil is precisely designated by some considerations such as wind deviations and practical restrictions. This work augmented by an optimization algorithm using the Simulated Annealing (SA) as a conceivable technique for the optimized deign of the proposed SMES coil. Finally, this paper represents the real-time energy management strategy for close coordination between the wind power, loads, and micro-SMES system according to power and current measurement. For this purpose, the novel approach for bi-directional DC-DC converter is expatiated corresponding an optimized charging and discharging model of the micro-SMES system.

\section{Overall System Configuration}

The proposed structure of the standalone dc microgrid system is schematically shown in Fig. 1. A wind turbine using permanent magnet synchronous generator (PMSG) based variable speed wind turbine (VSW T) rated at $1 \mathrm{MW}$ and $690 \mathrm{~V}$ is considered as main source of power generation. The generator-side converter including the three-phase voltage source converter (VSC), namely, W-VSC is connected the PMSG to the dc network. The energy storage (ES) system that is based on small-scale superconducting magnetic energy storage (SMES) technology is incorporated into the $\mathrm{dc}$ network through a bidirectional dc-dc converter as shown in Fig. 1.

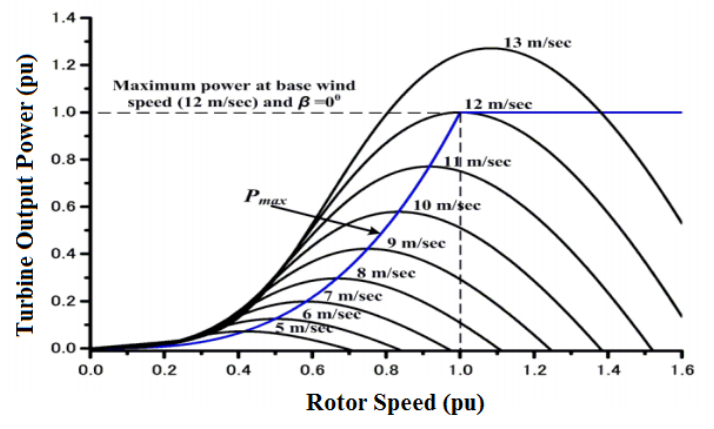

FIG. 2 TURBINE POWER CHARACTERISTIC $(\beta=0 \mathrm{o})$ [14].

An effective dump load is used to increase energy efficiency of the system by absorbing the excess power during the over wind generation. The surplus energy is employed in charging the SMES until current reach its upper limit. After that, the extra power is supplied to a proper dump load for heating purpose with DCDC converter.

The total output power of wind turbine is supplied to the variable dc loads including direct-connected and sensitive loads. During the prolonged operation in low wind mode, an appropriate load shedding must be considered in order to guarantee the system against total collapse and to cater a secure power supply to high priority loads (sensitive loads).

\section{Wind Turbine Modeling}

According to the Betz theory, extractable mechanical power from the wind can be determined by mathematical relation as follows [14]

$$
P_{w}=0.5 \rho \pi R^{2} V_{w}^{3} C_{P}(\lambda, \beta)
$$

where $\mathrm{Q}$ is the air density $[\mathrm{kg} / \mathrm{m} 3], \mathrm{R}$ is the blade radius $[\mathrm{m}], V_{w}$ is the wind speed $[\mathrm{m} / \mathrm{s}]$ and $C_{p}$ is the power coefficient which is a function of tip-speed ratio, $\lambda$, and the blade pitch angle, $\beta[\mathrm{deg}]$. In variable speed PMSG-based wind turbine, the obtained power depends on the power foxient. For each wind speed, the maximum power point can be acquired corresponding to certain rotor speed, $\omega \mathrm{m}$ that is given as

$$
P_{\max }=0.5 \rho \pi R^{2}\left(\frac{R \omega_{m}}{\lambda_{\text {opt }}}\right)^{3} C_{P-o p t}
$$

where $\lambda_{\text {opt }}$ and $C_{\text {p-opt }}$ are the optimum value of the tip speed ratio and power coefficient, respectively.

Fig. 2 illustrates the turbine output power as a function of the rot or speed for varying values of wind speeds with the blade pitch angle $\beta=0$. 


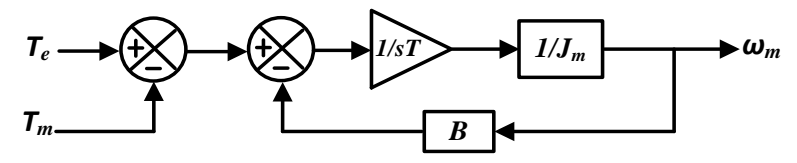

FIG. 3 MODELING OF WIND TURBINE SYSTEM DRIVE-TRAIN.

For an average wind speed of $12 \mathrm{~m} / \mathrm{s}$, which is used in this study, the turbine output power and generator speed are 1.0 p.u. The drive train of the wind turbine generator is specified by a one-mass model based on deriving the state equation for the rotor angular speed at the wind turbine, represented by

$$
\frac{d \omega_{m}}{d t}=\frac{1}{J_{m}}\left(T_{m}-T_{e}-B \omega_{m}\right)
$$

where $\mathrm{J}_{\mathrm{m}}$ is the moment of inertia for blades, hub and generator, $T_{m}$ is the mechanical torque, $T_{e}$ is the electric torque and $\mathrm{B}$ is rotational damping. The applied block diagram for modeling of wind turbine system drivetrain is shown in Fig. 3.

\section{SMES System Description}

In this study, the micro-SMES system is implemented as a promising energy storage system for load leveling and power stabilizing in standalone dc microgrid. Independent of capacity and size, a SMES system constantly consists of a superconducting coil which stores energy in the magnetic field generated by a circulating current, cryogenic refrigerator to keep coil at a low temperature required to maintain it in superconducting state and a power conditioning system (PCS) in order to transfer the energy from the SMES coil into the grid [15].

\section{SMES System Capacity}

Although the balancing performance of SMES coil can be increased by selecting a larger capacity, the cost installation of SMES system will rise accordingly, making the implementation of SMES unviable. Conversely, choosing an inadequate capacity for SMES system will most likely lead to ineffective operation for minimizing wind power fluctuations. Thus the coil capacity depending on its application and charging/discharging duration must be carefully selected.

For dc microgrid equipped by VSWT-PMSG, if microSMES balances the fluctuating power $\pm \Delta \mathrm{P}_{\text {wind }}$ for a period of $\Delta \mathrm{t}$ seconds, the SMES requires to compensate $\pm \Delta P_{\text {wind }} \times \Delta t$ stored energy duo to the intermittent wind fluctuations.

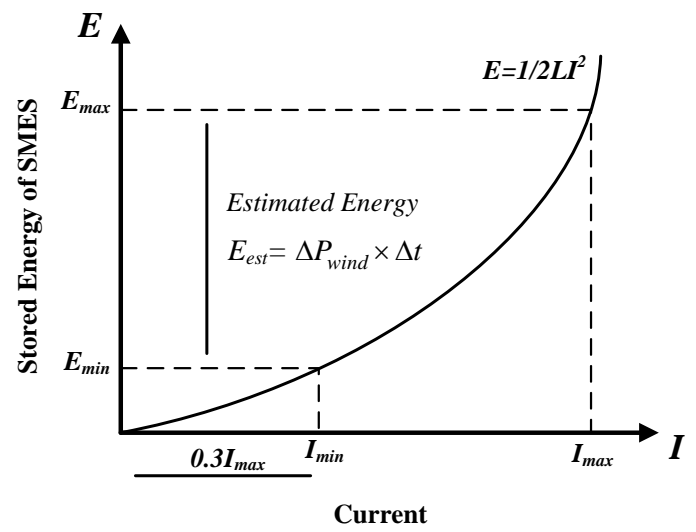

FIG. 4 ESTIMATED ENERGY OF THE MICRO-SMES BASED ON LOWER AND UPPER COIL CURRENT LIMITS

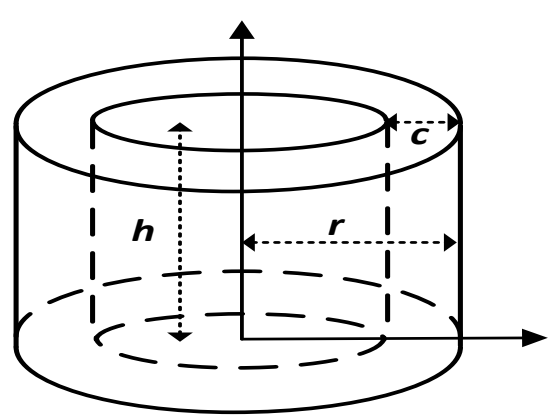

FIG. 5 THE CROSS SECTION OF MULTI-LAYER SOLENOID COIL.

As stated in (1), the wind power is proportional to the third power of wind speed. If the standard deviation of wind speed fluctuations is $20 \%$ of the average wind speed, the output powefiluctuations will be about $80 \%\left(\Delta \mathrm{P}_{\text {wind }}=800 \mathrm{~kW}\right.$ for a period of 1 second $)$ of the rated $1 \mathrm{MW}$ from the wind power. Therefore, the capacity requirement of the SMES system can be estimated as following

$$
E_{\text {est }}=\Delta P_{\text {wind }} \times \Delta t=800 \mathrm{~kW} \times 1 \mathrm{~s}=800 \mathrm{~kJ}
$$

In practice, in order to prevent the possibility of discontinuous conduction under unpredicted disruptions, SMES current, Ismes is not permitted to reach zero [12]. Fig. 4 shows the relation between the stored energy of the SMES and the available energy for the wind turbine based on lower and upper coil current limits $\left(0.3 \mathrm{I}_{\max }<\mathrm{I}_{\text {smes }}<\mathrm{I}_{\max }\right)$. Here, $\mathrm{E}_{\max }$ can be calculated from (4) and Fig. 4 which has a relation as

$$
E_{\max }=\frac{E_{\text {est }}}{\left(1-0.3^{2}\right)}=880 \mathrm{~kJ}
$$

\section{Design of Micro-SMES Coil}

The magnet for micro-SMES coil usually is based on a low temperature superconductor (LTS) niobiumtitanium (NbTi) alloy. To reach the superconducting state, the coil has to be cooled to less than $4.2^{\circ} \mathrm{K}$ by 
liquid helium [8]. In this research, the coil was to be made of NbTi LTS tape that was manufactured by the Furukawa Electric Co., Japan. The cross area of one superconducting filament is $2.07 \times 1.07 \mathrm{~mm}^{2}$ including insulation [16]. Despite, a SMES coil has been constructed in many different shapes but one of the most common kinds is the solenoid type winding which are widely used because of their simple structure, feasibility to manufacture and high efficiency.

In order to facilitate the manufacturing a SMES coil with LTS tape, several turns of the coil arrangement can be assumed in a cylindrical fashion, as shown in Fig. 5, where h, r, and c are the height, the mean radius, and the radial thickness of the solenoid coil, respectively.

\section{Superconducting Coil Optimization}

An optimal design of a solenoid coil volume will influence the cost and the size of the overall SMES and, thereby allows for the use of a smaller and more compact design. Thus, the coil volume is set as objective function of this paper for the optimal microSMES design. The considered objective function, i.e., minimum coil volume for the two constraints, expected stored energy and allowable risk factor can be expressed as following:

$$
\begin{aligned}
& \text { Object : } \min V_{\text {coil }}=\pi\left[(r+c / 2)^{2}-(r-c / 2)^{2}\right] \times h \\
& \text { Subject to : }
\end{aligned}
$$

$$
\left\{\begin{array}{l}
\frac{\left|E_{\text {smes }}-E_{\max }\right|}{E_{\max }} \leq \varepsilon \\
R_{f}=\frac{J}{J_{c}} \leq \gamma
\end{array}\right.
$$

where $E_{\text {smes }}$ is the energy actually stored in the coil, Emax is the expected stored energy $(880 \mathrm{~kJ}) . \varepsilon$ is the maximum relative error of Emax, which is set as $1 \%$. $\mathrm{J}$ is the current density in the coil, and $\mathrm{J}_{\mathrm{c}}$ is the critical current density of LTS tape, usually depends on the maximum magnetiflux density $B$ max at given temperature. $\gamma$ is the maximum allowable risk factor value and is assumed to be 0.7 . This optimization is accomplished by an algorithm based on simulated annealing (SA) which is a feasible method for an optimized design of the SMES solenoid.

SA is a method to obtain an optimal solution for a single-objective optimization problem. It is based on an analogy of thermodynamics with the way metals cool and anneal. If liquid metal is cooled slowly, its atoms form a pure crystal corresponding to the state of
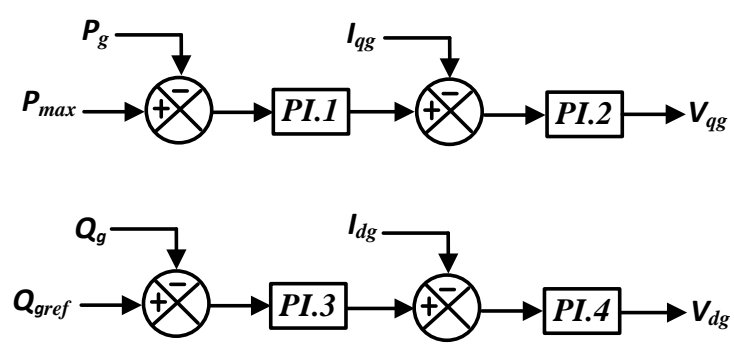

FIG. 7. GENERATOR SIDE CONTROLLER OF PMSG.

Minimum energy for the metal. The metal reaches a state with higher energy if it is cooled quickly. This algorithm has ability to escape from local minima and can deal with discrete variables [8], [17].

\section{Control Scheme in Standalone Mode}

The implemented control scheme used in dc microgrid including a W-VSC and DC-DC chopper is shown in Fig. 6. The primary requirement for standalone operation mode is to maintain the common dc bus voltage within an acceptable range $(0.95 \mathrm{pu}$ and 1.05 pu) under any condition. Indeed, a constant dc voltage designates balanced active powflow among the wind power, SMES system and dc loads.

\section{VSC Converter Control}

The voltage source converter consists of six IGBTs switch interconnected as a full-bridge converter that is directly connected to the stator of the PMSG. The control block diagram for VSC converter shown in Fig. 7 , is based on the synchronous $\mathrm{d}-\mathrm{q}$ reference frame. The active power reference, $P_{\max }$, is determined from maximum power point tracking (MPPT) in such a way, as pointed out previously. Also, the reactive power produced by the wind turbine is regulated at zero MVar $\left(Q g_{\text {ref }}=0\right)$ under normal operating conditions. In W-VSC converter, the triangle signal is used as the carrier wave of PWM operation. The carrier frequency is chosen $10 \mathrm{kHz}$ for VSC converter. The dc-link capacitor value is $50000 \mu \mathrm{F}$ while the rated dc-link voltage across the two capacitor legs is $1.2 \mathrm{kV}$.

\section{Two-Quadrant DC-DC Converter Control}

The micro-SMES coil is interconnected on to the dc link through a dc-dc bi-directional converter to facilitate an active power flow in both directions as shown in Fig. 6. It is assumed to be fully charged at its maximum capacity of $880 \mathrm{~kJ}$. The two IGBTs, GA and $\mathrm{G}$ в are controlled using hysteresis band current control technique. 


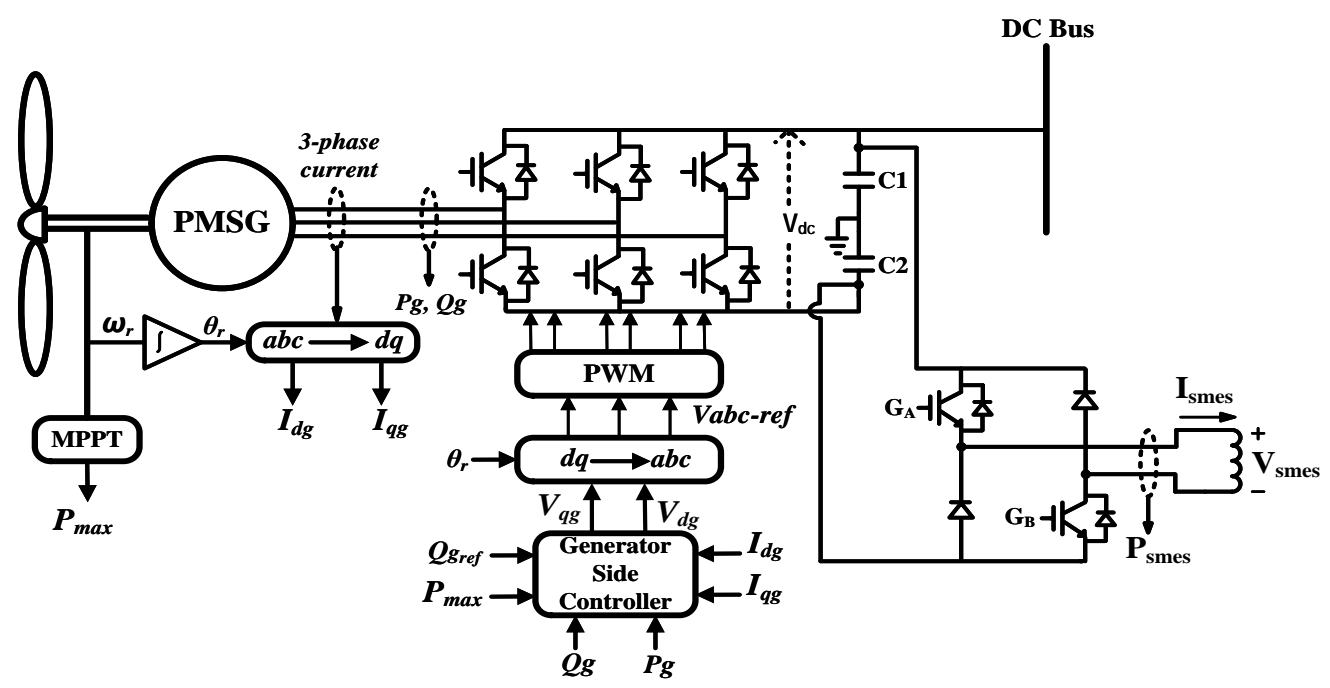

FIG. 6 CONTROL DIAGRAM OF PMSG-BASED VARIABLE SPEED WIND TURBINE.

The control of the IGBTs is carried out by comparison of generating power with the wind turbine, Pwind and power consumed by the load, Pload, In order to maintain system stability, the micro-SMES system must be charged or discharged corresponding to the necessary power balancing as

$$
P_{\text {smes }}^{*}=P_{\text {wind }}-P_{\text {load }}
$$

where superscript * represents the required (reference) value. For the acceptable operation of the dc microgrid during the variations of wind generation, three regions of operation can be identified for the dc-dc converter.

Standby mode: it takes place when output power of the wind turbine is equal to the load power $\left(\mathrm{P}^{*}{ }_{\text {smes }}=0\right)$. The SMES coil current is kept constant at its rated value. Consequently, there will be no energy transferred between the micro-SMES system and dc microgrid.

Discharging mode: it will occur when output power of the wind turbine is smaller than the rated power $\left(\mathrm{P}^{*}\right.$ smes $<0)$. In this case, the required power is being delivered to the dc link capacitor with dc-dc converter.

Charging mode: it will occur when output power of the wind turbine is greater than the rated power $\left(\mathrm{P}^{*}\right.$ smes $\left.>0\right)$. Under this condition, the surplus of the wind power is being transferred to the SMES coil. For a dc microgrid system, required energy during power imbalance and Ismesi, SMES coil current at end of the exchanging period, $\mathrm{T}$ is given as

$$
E_{\text {smes }}^{*}=\int_{T} P_{\text {smes }}^{*} \cdot d t
$$

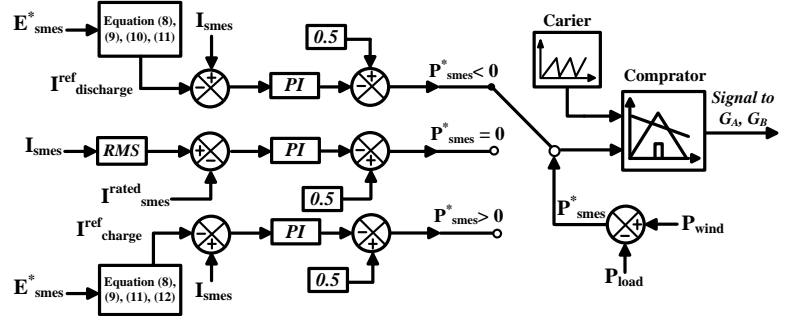

FIG. 8 CONTROL DIAGRAM OF DC-DC CONVERTER WITH SMES COIL.

$$
I_{\text {smes }, 1}=\sqrt{I_{\text {smes } 0}^{2}-\frac{2 \times E_{\text {smes }}^{*}}{L_{\text {smes }}}}
$$

where $E_{\text {smes }}^{*}$ is energy exchange between micro-SMES system and dc link $(\mathrm{J})$, Lsmes is the coil inductance $(\mathrm{H})$ while Ismeso represents the coil current at the beginning of the exchanging period. In this effort, it is assumed that the superconducting coil is being charged or discharged based on an exponential function shown by the following equations.

$$
\begin{gathered}
I_{\text {discharge }}^{\text {ref }}=I_{\text {smes }, 0} \times e^{-\alpha\left(t-t_{d}\right)} \\
I_{\text {charge }}^{\text {ref }}=-I_{\text {smes }, 1} \times e^{-\beta\left(t-t_{d}\right)} \\
\alpha=\beta=\frac{1}{T} \times \operatorname{Ln}\left(\frac{I_{\text {smes } 0}}{I_{\text {smes } 1}}\right)
\end{gathered}
$$

The proper operation of the control system is occurring when coil current pursues these reference currents during the charging/discharging operation mode. In order to generate the gate signals for the $G_{A}$ and $G_{в}$, the reference duty cycle signals must be compared with the carrier with the frequency of $4 \mathrm{kHz}$. 
The schematic of the dc-dc converter controller used to regulate the current of the SMES to maintain the dc bus voltage constant is depicted in Fig. 8. In order to generate the gate signals for the $G_{A}$ and $G_{B}$, the reference duty cycle signals must be compared with the carrier with the frequency of $4 \mathrm{kHz}$. The schematic of the dc-dc converter controller used to regulate the current of the SMES to maintain the dc bus voltage constant is depicted in Fig. 8.

\section{Real-Time Energy Management System}

A comprehensive load management strategy is introduced in; Wind power and Photovoltaics are considered as smart agents which are utilized for distribution network load management [18]. Another effective mean for energy management is demand response programs utilization considering the high penetration of plug-in hybrid electric vehicles [19]. In order to optimize energy utilization specifically during long-term low-wind or high-wind period, an appropriate real-time power management must be incorporated into the control system to maintain the dc bus voltage constant. The flowchart for the suggested energy management algorithm, which accounts for two scenarios, is annotated in Fig. 9. Scenario 1: if the maximum available power from the VSWT-PMSG is greater than demand, the excess power $\left(\mathrm{P}_{\text {smes }}^{*}\right)$ can be used to charge the SMES coil until current reaches its upper limit $\left(I_{\max }\right)$. In this case, SMES system is set in standby mode and extra power is supplied to a proper dump load. However, this condition is not considered in the study.

Scenario 2: In cases where power from the wind turbine is not enough to meet the demand, the SMES needs to be discharged in order to prevent the total voltage collapse of the dc microgrid. Similarly, if SMES coil current exceed lower limit $\left(0.3 I_{\max }\right)$, the nonsensitive load will be automatically disconnected and micro-SMES system will switch its control from discharging to charging mode to absorb extra wind power according to latest reduced demand.

\section{Simulation Results and Discussion}

In this section, simulation studies are carried out to verify the effectiveness of the standalone dc microgrid using PMSG-based wind turbine and micro-SMES system is shown in Fig.1. The evaluation technique described in Section $\mathrm{V}$ is applied to the dc microgrid to enhance system efficiency from viewpoints of cost cutting, energy savings, and downsizing.

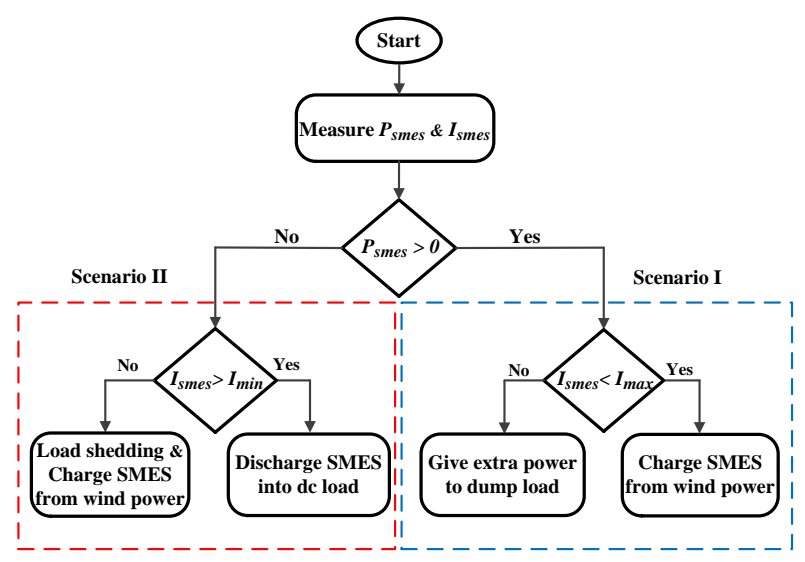

FIG. 9 ENERGY MANAGEMENT STRATEGIES FOR THE STANDALONE DC MICROGRID.

\section{Optimal Scheme Performance}

A simulated annealing (SA) method is employed for the design of an optimal SMES solenoid coil. The optimization solution is obtained by performing certain number of iterations, leading to an optimal design. The constraints of the selected variables for the optimization problem are expressed as following

TABLE I OPTIMIZATION RESULTS OF THE SMES COIL

\begin{tabular}{cc}
\hline \hline Parameter & Quantity \\
\hline \hline Height of the coil $h$ & $256 \mathrm{~mm}$ \\
Mean radius of the coil $r$ & $438 \mathrm{~mm}$ \\
Radial thickness of the coil $\chi$ & $150 \mathrm{~mm}$ \\
Inductance of the coil $L$ & $7 \mathrm{H}$ \\
\hline \hline$r \in[400,600] \mathrm{mm}$ & \\
$\mathrm{c} \in[100,200] \mathrm{mm}$ & \\
$h \in[200,400] \mathrm{mm}$ &
\end{tabular}

Fig. 10 shows the progression of the solution of the optimization problem whereas the objective concentrates on an optimal point, $V_{\text {coil }}=0.105 \mathrm{~m}^{3}$, during cooling in the annealing process. The optimized coil size and corresponding SMES coil inductance are shown in Table I. According to the above results, the maximum currentflowing through the coil at steady state can be obtained

$$
I_{\text {max }}=\sqrt{\frac{2 \times E_{\max }}{L_{\text {coil }}}}=500 \mathrm{~A}
$$

\section{Case Studies}

The proposed system is modeled and simulated by PSCAD/EMTDC software. As can be seen from Fig. 1, 


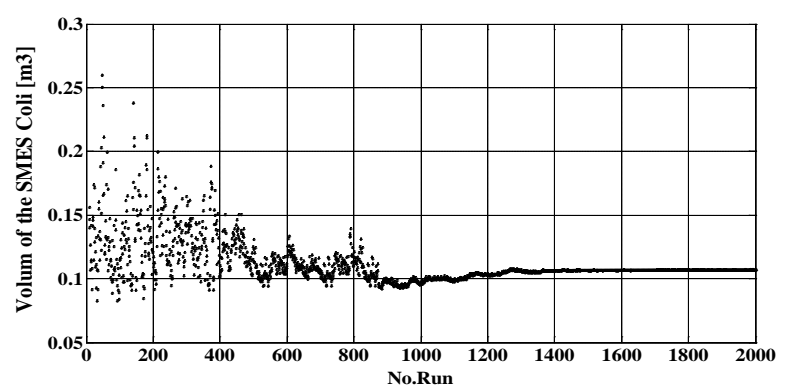

FIG 10. PROGRESS OF THE SOLUTION OF THE PROPOSED OPTIMIZATION CONSIDERING Vcoil AS OBJECTIVE FUNCTION.

It is made up of the PMSG-based wind turbine rated at $1 \mathrm{MW}$ and $690 \mathrm{~V}$ and an $1 \mathrm{MW}$ W-VSC with switching frequency $10 \mathrm{kHz}$. Ll and L2 are constant power loads both rated at $330 \mathrm{~kW}$, while $\mathrm{Ll}$ (sensitive load) is the most important load and cannot be switched out during operation. For a wind speed of $11 \mathrm{~m} / \mathrm{s}$, the wind turbine deliver rated power $660 \mathrm{~kW}$ to the loads as shown in Fig. 2. The micro-SMES system consisting of the superconducting coil with capacity of $880 \mathrm{~kJ}$ and the bi-directional dc-dc converter is connected to the $1.2-\mathrm{kV}$ bus via the dc-link capacitor. To ensure that the proposed micro-SMES operates properly, the supervisory control architecture previously outlined is analyzed by considering the following cases:

\section{1) Case 1: Normal Charging/Discharging \\ Operation}

Fig. 11 depicts simulation results for Case 1 including normal charging and discharging operation. The simulation starts in wind speed of $11 \mathrm{~m} / \mathrm{s}$ and $\mathrm{L}_{1}, \mathrm{~L}_{2}$ are switched in $\left(\mathrm{P}_{\text {load }}=660 \mathrm{~kW}\right)$ as shown in Fig 11(a) and Fig 11(c), respectively. When the torque reference is reduced to $0.63 \mathrm{pu}$, the wind turbine power is equal to the overall load as seen in Fig. 11(d). The micro-SMES coil fully charges at its maximum current of $500 \mathrm{~A}$. At $6 \mathrm{~s}$, the wind speed changes to $9 \mathrm{~m} / \mathrm{s}$ and wind turbine power reduces to $290 \mathrm{~kW}$ which is less than demand thus the required power, $370 \mathrm{~kW}$ must be supplied by the micro-SMES system to keep load power constant at $660 \mathrm{~kW}$ (discharging mode). The micro-SMES current is reduced to approximately $282 \mathrm{~A}$ as a result of the discharging mode as shown in Fig. 11 (b).

At around $7.5 \mathrm{~s}$, wind speed comes back to $11 \mathrm{~m} / \mathrm{s}$ and the SMES current remains in standby mode, drawing no power not supplying power to the dc microgrid. At $10 \mathrm{~s}$, the wind speed goes up to 12 $\mathrm{m} / \mathrm{s}$ and subsequently does the generated power, $900 \mathrm{~kW}$, as

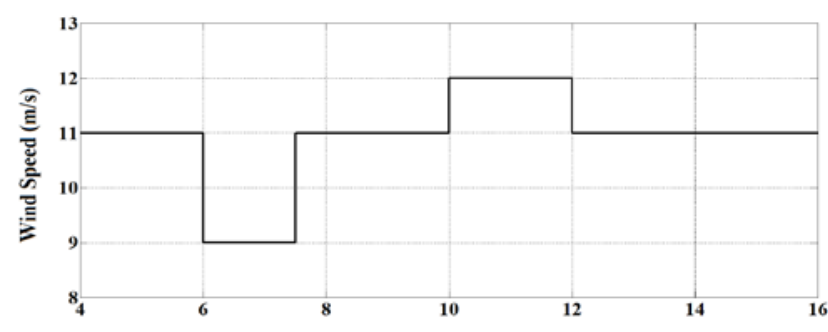

(a)

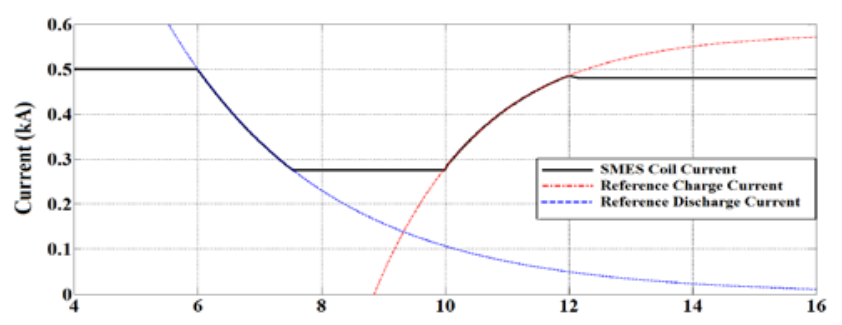

(b)

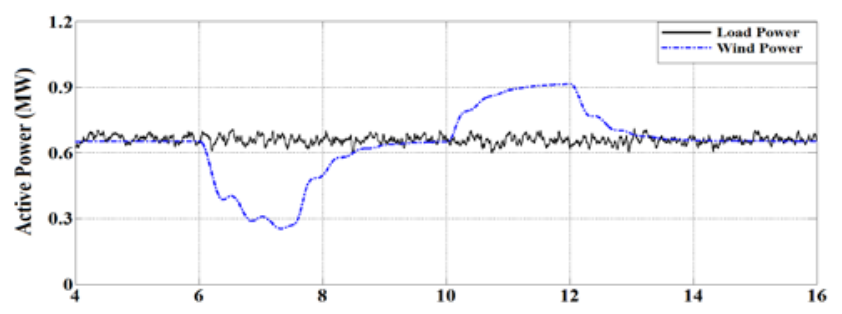

(c)

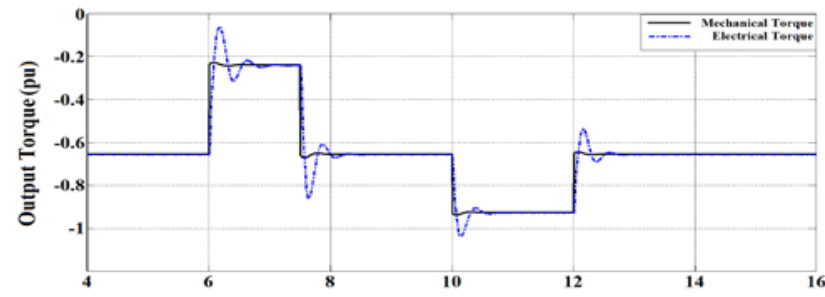

(d)

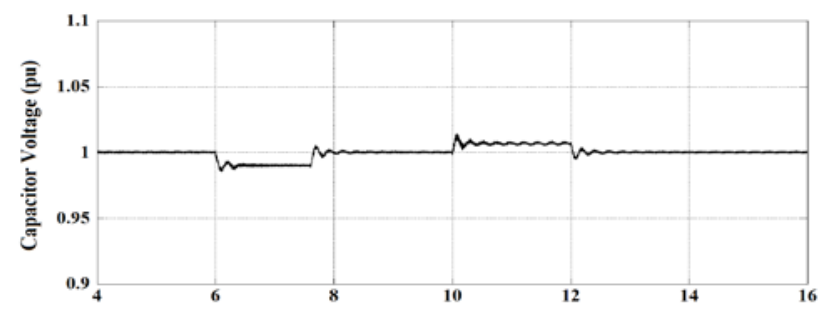

(e)

Time (s)

FIG. 11. SYSTEM OPERATION DURING NORMAL CHARGING/DISCHARGING MODE (CASE 1). (a) WIND SPEED. (b) SMES COIL CURRENT. (c) POWER GENERATED BY THE WIND TURBINE AND TOTAL LOAD. (d) OUTPUT MECHANICAL AND ELECTRICAL TORQUE. (e) DC-LINK VOLTAGE.

Seen in Fig. 11(c). The excess power, $340 \mathrm{~kW}$ must be drawn by micro-SMES system to keep the dc voltage less than 1.05 p.u. Under this condition, coil current rises from $282 \mathrm{~A}$ to $485 \mathrm{~A}$ and the microSMES capacity will be again set at around the 
maximum amount. The charging and discharging currents exactly track the reference currents as shown in Fig. 11(b). Obviously, it is found that the performance of proposed control method is entirely acceptable.

In Fig 11 (d), the dynamic characteristic of the wind turbine is clarified by presented model of drive train in which produced torque follows the optimum mechanical torque of the turbine according to the above-mentioned wind speed. The output dc-link voltage at the constant load is presented in Fig. 11 (e) which is well controlled by micro-SMES system.

\section{2) Case 2: Long-Term Low-Wind Operation}

Simulation results of system control and operation corresponding to Case 2 are shown in Fig. 12. Similarly, at the first of simulation, all the situations are the same with before case between 4 $\mathrm{s}$ and $6 \mathrm{~s}$.

At $6 \mathrm{~s}$, the wind speed drapes from $11 \mathrm{~m} / \mathrm{s}$ to 10 $\mathrm{m} / \mathrm{s}$ for a period of $2 \mathrm{~s}$. In this condition, the microSMES system increases its power output to compensate this in order to maintain the dc-link voltage at 0.97 p.u. [Figs. 12(a) and (e)]. At around $9 \mathrm{~s}$, the micro-SMES current is reduced to $150 \mathrm{~A}$ which is the equal to threshold value (0.3Imax). Under this condition, the system tries to reserve energy for the most important load (i.e., L1 in this example). Thus, L2 $(330 \mathrm{~kW})$ is tripped and the SMES can now start to get charged as can be seen from Figs. 12(b) as the wind turbine generates more power than the latest reduced demand (L1).

After tripping L1 for $1 \mathrm{~s}$, at $10 \mathrm{~s}$, the wind speed increases to $12 \mathrm{~m} / \mathrm{s}$ and the micro-SMES gradually gets charged to roughly $860 \mathrm{~kW}$ and L2 reconnect to the microgrid as shown in Fig. 12(c).at the end of this period coil current reach 375 A [see Fig. 12(b)].

At $12 \mathrm{~s}$, wind speed comes back to $11 \mathrm{~m} / \mathrm{s}$ to provide total load $(660 \mathrm{~kW})$ while torque reference is set to $0.63 \mathrm{pu}$ as seen in Fig. 12(d). Finally, at $14 \mathrm{~s}$, the wind speed decreases again to $10.5 \mathrm{~m} / \mathrm{s}$ and wind turbine power reduces to $545 \mathrm{~kW}$ which is less than demand thus the required power, $115 \mathrm{~kW}$ must be provided by the micro-SMES system. As seen from Figs. 12(d) and (e), the dynamic characteristic of the wind turbine and dc-link voltage are well controlled during various operating conditions, and the proposed control strategy is satisfactory.

\section{Conclusion}

This work has been studied the micro-SMES system embedded to the VSWT-PMSG that is interconnected to the standalone dc microgrid through the bidirectional DC-DC converter.

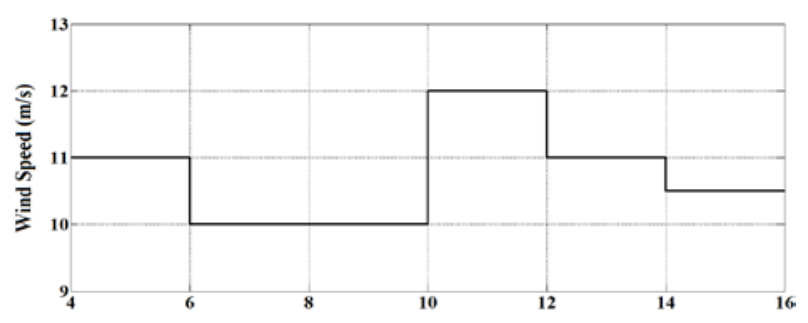

(a)

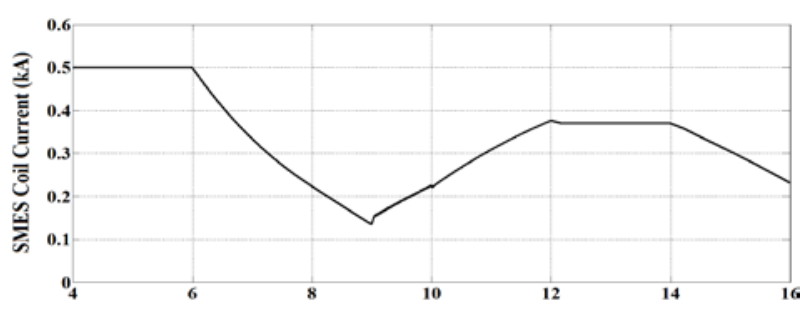

(b)

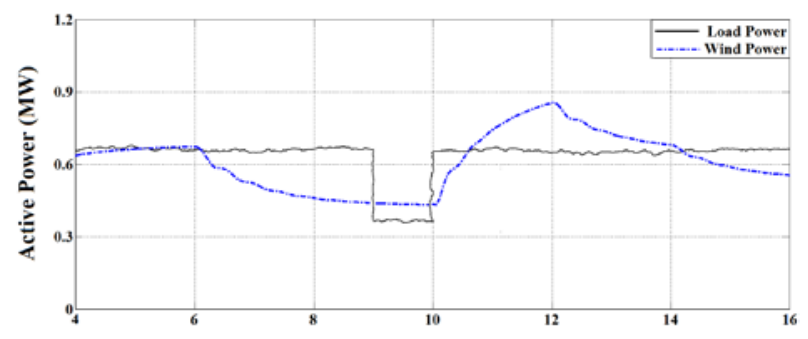

(c)

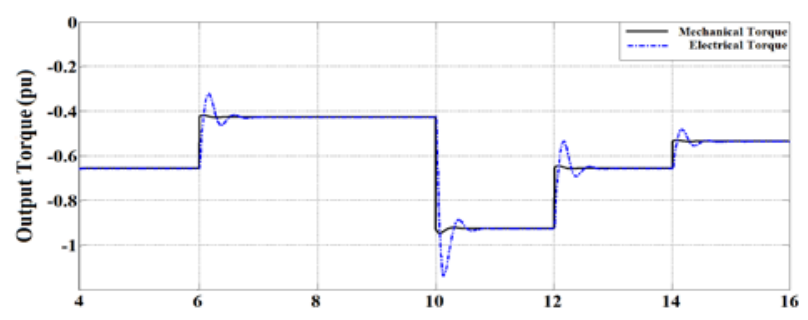

(d)

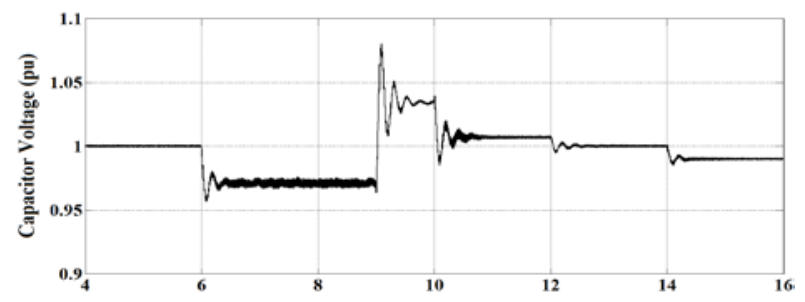

(e)

Time

FIG. 12. SYSTEM OPERATION DURING PROLONGED LOWWIND MODE (CASE 2). (a) WIND SPEED. (b) SMES COIL CURRENT. (c) POWER GENERATED BY THE WIND TURBINE AND TOTAL LOAD. (d) OUTPUT MECHANICAL AND ELECTRICAL TORQUE. (e) DC-LINK VOLTAGE. 
The power balance between loads, micro-SMES system and nondeterministic wind generation has been maintained via presenting the supervisory control architecture. For this purpose, an optimal design scheme based on SA algorithm has been modeled for micro-SMES solenoid coil to ensure the desired energy storage capacity $(880 \mathrm{~kJ})$ with least volume. Moreover, this paper presents a effective control strategy to obtain a rapid response of the micro-SMES system to the wind speed fluctuations in order to stabilize dc-link voltage; thereby smoothing the output power simultaneously. This penetrative approach allows finding the optimized charging and discharging model based on the exponential function. System simulations corresponding to the aforementioned operational modes have confirmed the satisfactory maneuver of the proposed dc microgrid.

\section{REFERENCES}

Guerrero, J.M.; Blaabjerg, F.; Zhelev, T.; Hemmes, K.; Monmasson, E. "Distributed Generation: Toward a New Energy Paradigm," Industrial Electronics Magazine, IEEE , vol.4, no.1, pp.52,64, March 2010.

Farhadi, M.; Mohammed, O., "Realtime Operation and Harmonic Analysis of Isolated and Non-Isolated Hybrid DC Microgrid," Industry Applications, IEEE Transactions on , vol.PP, no.99, pp.1,1.

N. Hatziargyriou, H. Asano, R. Iravani, and C. Marnay, “Microgrids," IEEE Power Energy Mag., vol. 5, no. 4, pp. 78-94, Jul./Aug. 2007.

T. Senjyu, T. Nakaji, K. Uezato, and T. Funabashi, “A hybrid power system using alternative energy facilities in isolated island," IEEE Trans. Energy Convers., vol. 20, no. 2, pp. 406-414, Jun. 2005.

F. Valenciaga and P. Puleston, "Supervisor control for a stand-alone hybrid generation system using wind and photovoltaic energy," IEEE Trans. Energy Convers., vol. 20, no. 2, pp. 398-405, Jun. 2005.

Bhende, C.N.; Mishra, S.; Malla, S.G., "Permanent Magnet Synchronous Generator-Based Standalone Wind Energy Supply System," Sustainable Energy, IEEE Transactions on , vol.2, no.4, pp.361,373, Oct. 2011.

Lie $\mathrm{Xu}$; Dong Chen, "Control and Operation of a DC Microgrid With Variable Generation and Energy
Storage," Power Delivery, IEEE Transactions on, vol.26, no.4, pp.2513, 2522, Oct. 2011.

Moghadasi, A.H.; Heydari, H.; Farhadi, M., "Pareto Optimality for the Design of SMES Solenoid Coils Verified by Magnetic Field Analysis," Applied Superconductivity, IEEE Transactions on , vol.21, no.1, pp.13,20, Feb. 2011.

Moghadasi, A.; Torabi, S.M.; Salehifar, M., "Combined operation of the unified power quality conditioner with SFCL and SMES," Power Quality Conference (PQC), 2010 First, vol., no., pp.1,7, 14-15 Sept. 2010.

Mustafa Farhadi, Hossein Heydari, "Rational approach for self-limiting current injection transformers confirmed by coupled electromagnetic-thermal FEM simulation," Supercond. Sci. Technol, vol.24, no.7, 2011.

Nomura, S.; Ohata, Y.; Hagita, T.; Tsutsui, H.; Tsuji-Iio, S.; Shimada, R., "Wind farms linked by SMES systems," Applied Superconductivity, IEEE Transactions on, vol.15, no.2, pp.1951,1954, June 2005.

Louie, Henry; Strunz, K., "Superconducting Magnetic Energy Storage (SMES) for Energy Cache Control in Modular Distributed Hydrogen-Electric Energy Systems," Applied Superconductivity, IEEE Transactions on, vol.17, no.2, pp.2361, 2364, June 2007.

H. Kakigano, Y. Miura, and T. Ise, "Low-voltage bipolartype DC microgrid for super high quality distribution," IEEE Trans. Power Electron., Vol. 25, No. 12, pp. 30663075, Dec. 2010.

Rosyadi, M.; Muyeen, S. M.; Takahashi, R.; Tamura, J., "Low voltage ride-through capability improvement of wind farms using variable speed permanent magnet wind generator," Electrical Machines and Systems (ICEMS), 2011 International Conference on, vol., no., pp.1,6, 20-23 Aug. 2011.

Ribeiro, P.F.; Johnson, B.K.; Crow, M.L.; Arsoy, A.; Liu, Y., "Energy storage systems for advanced power applications," Proceedings of the IEEE, vol.89, no.12, pp.1744, 1756, Dec 2001.

Guiping Zhu; Ming Song; Zanji Wang; Shaotao Dai, "Design of LTS Coil Used for the Combined Device of SMESSFCL," Applied Superconductivity, IEEE Transactions on, vol.16, no.2, pp.674, 677, June 2006. 
Heydari, H.; Moghadasi, A.H., "Optimization Scheme in Combinatorial UPQC and SFCL Using Normalized Simulated Annealing," Power Delivery, IEEE Transactions on , vol.26, no.3, pp.1489,1498, July 2011.

M.H. Amini, B. Nabi and M. -R. Haghifam, “Load management using multi-agent systems in smart distribution network," IEEE PES General Meeting, Vancouver, BC, Canada, 2013.

M.H. Amini, B. Nabi, M. Parsa Moghaddam and S.A. Mortazavi, " Evaluating the Effect of Demand Response Programs and Fuel Cost on PHEV Owners Behavior, A Mathematical Approach",Second Iranian Conference on Smart Grid, 2012.

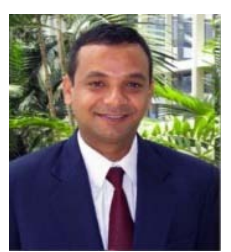

Arif I. Sarwat received his M.S. degree in Electrical and Computer Engineering from the University of Florida, Gainesville. In 2010, he received his Ph.D. degree in Electrical Engineering from the University of South Florida. Dr. Sarwat worked in the industry (SIEMENS) for nine years executing many critical projects. Before joining the Florida International University, he was Assistant Professor of Electrical Engineering at the
University at Buffalo, the State University of New York (SUNY). He is co-developer of the DOE funded Gateway to Power (G2P) Project along with FPL/NextEra company. His significant work in Energy Storage, Micro-Grid and Demand Side Management (DSM) is demonstrated by Sustainable Electric Energy Delivery Systems in Florida. He is also coprinciple investigator in the study of reliability \& predictability of highly penetrated renewable resources power plants (DOE funded Sunshine State Solar Grid Initiative (SUNGRIN). His research areas are Smart Grids, High Penetration of Renewable Systems, Power System Reliability, Large Scale Distributed Generation Integration, Large Scale Data Analysis, Distributed Power Systems, Demand Side Management, Communication, Power System Optimization and Cyber Security.

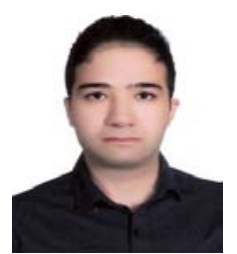

Amirhasan Moghadasi received the M.Sc. degree in electrical engineering from Iran University of Science and Technology (IUST), Tehran, Iran, in 2009. He is currently cooperating with Energy, Power \& Sustainability Laboratory in Florida International University as $\mathrm{PhD}$ student. His research interests are integrating of renewable energy resources, power electronic, applied superconducting in power systems, and optimization methods. 